\title{
Robust Backstepping Control for Cold Rolling Main Drive System with Nonlinear Uncertainties
}

\author{
Xu Yang, ${ }^{1,2}$ Kai-xiang Peng, ${ }^{1}$ and Chao-nan Tong ${ }^{1}$ \\ ${ }^{1}$ Key Laboratory of Advanced Control of Iron and Steel Process (Ministry of Education), School of Automation and \\ Electrical Engineering, University of Science and Technology Beijing, Beijing 100083, China \\ ${ }^{2}$ State Key Laboratory of Mechanical System and Vibration, Shanghai Jiao Tong University, Shanghai 200240, China
}

Correspondence should be addressed to Kai-xiang Peng; kaixiang@ustb.edu.cn

Received 13 November 2013; Accepted 4 December 2013

Academic Editor: Ming Liu

Copyright @ $2013 \mathrm{Xu}$ Yang et al. This is an open access article distributed under the Creative Commons Attribution License, which permits unrestricted use, distribution, and reproduction in any medium, provided the original work is properly cited.

\begin{abstract}
The nonlinear model of main drive system in cold rolling process, which considers the influence with parameter uncertainties such as clearance and variable friction coefficient, as well as external disturbance by roll eccentricity and variation of strip material quality, is built. By transformation, the lower triangular structure form of main drive system is obtained. The backstepping algorithm based on signal compensation is proposed to design a linear time-invariant (LTI) robust controller, including a nominal controller and a robust compensator. A comparison with PI controller shows that the controller has better disturbance attenuation performance and tracking behaviors. Meanwhile, according to its LTI characteristic, the robust controller can be realized easily; therefore it is also appropriated to high speed dynamic rolling process.
\end{abstract}

\section{Introduction}

The main drive system in cold rolling mill, as a high accuracy mechanical-electrical system, plays an important role in high speed stable rolling operation. However, the torsional vibration which usually occurs in main drive system has been recognized as a major restriction to the increase of strip yield and improvement of product quality $[1,2]$. It may lead to large gauge variations [3] of strip as well as the instability of rolling speed and can even cause damage to the mechanical equipment of mill stands $[4,5]$. As a matter of fact, the phenomenon of vibration exists generally in rolling process, but the time and location of where it happens cannot be easily predicted. Moreover, there are many factors that can cause the occurrence of torsional vibration, such as unstable state of friction in rolling deformation zone [6], asynchronous working between upper and lower work rolls [7], defects or failure in reduction gear box [8], influence of high order electrical harmonics excitation [9], and so on. Thus, all of these factors will cause a huge difficulty to operators on vibration-related fault detection [10-13] and suppression [14].
In order to analyze and control torsional vibration, many researchers have done a lot of work in studying the chatter mechanism. Although these mechanisms, such as negative damping effect and model matching have been identified after years of research, no clear and definite theory of their mechanics has emerged. One of the most important factors responsible for this situation is the oversimplified by neglecting nonlinearities in mechanical-electrical system, then the models can hardly be suitable for the vibration mechanism and the further control algorithms designation. Variable stiffness due to clearance in gearbox and friction coefficient should me most concerned among these nonlinearities, since the existence of nonlinear friction and stiffness terms have become the obstacle to modifying system dynamic characteristics.

In addition to studying vibration mechanism in main drive system with the consideration of nonlinearity, the control strategy is also a key point in vibration suppression. With the higher demand on speed and accuracy in modern cold rolling process, the traditional control method, such as PID, has not been qualified to manage those vibration 
pheromones, and some advanced control algorithms $[15,16]$ are not suitable to deal with the problem of model nonlinearity in rolling process. Thus, a nonlinear control algorithm is necessary to deal with this situation.

One of the recent breakthroughs in nonlinear control theory is the introduction of backstepping algorithms. The relative-degree constraints over parameterization and growth condition are removed by allowing the controlled plant to be nonlinearly dependent on structure uncertainty, such as unknown parameters or unmodeled time-varying disturbances [17-20]. Although there are many advantages in backstepping algorithm, the "explosion of complexity" problem $[18,21]$, caused by repeated differentiation, cannot be ignored due to its increase in calculation complexity, therefore making severe time delay on control output, which can directly influence the operation performance in cold rolling mills. In this paper, a more general case is discussed, where uncertainties are not required to satisfy matching condition or to be smooth, and then a robust control method based backstepping algorithm is introduced. The feature of this approach is that the designed controller is an LTI one, so the controller can be easily realized, and then the "explosion of complexity" can be avoided.

The major objective pursued in this paper is to formulate a reasonable nonlinear model with parameter uncertainty and external disturbance of cold rolling main drive system, including variable stiffness by clearance, changeable friction coefficient due to relative speed between work roll and strip, and external disturbance by load variation under dynamic working conditions. Furthermore, after proper model transformation, a robust backstepping control algorithm is stated. Finally, within actual industrial data, simulation result shows the good performance and tracking behaviors of this proposed approach, even under the influence of parameter uncertainties and external disturbances.

\section{Problem Description}

2.1. Mathematical Model of Main Drive System. Based on our former research, the main drive system of cold rolling mill can be defined as a "Mass-Spring System", including motor, shaft, gearbox, roll, and so on. Reasonable simplification is necessary for a better analysis of the dynamic behaviors in rolling system, which makes two parts of main drive system, mass system such as motor, as well as roll and spring system like gearbox and shaft. Therefore, the two-degreesof-freedom model within clearance, nonlinear friction coefficient, and load disturbance is established in this section. The dynamic structure of main drive system is shown in Figure 1, where $J_{1}, J_{2}$ is the moment of inertia of motor and load, $M_{1}$ is the drive torque of motor, $M_{2}$ is the torque of load with load disturbance, $K_{12}$ is defined as torsional stiffness coefficient of flexible shaft, $C_{1}, C_{2}{ }^{\prime}$ is the damping coefficient of motor, rolls, and shaft separately, $\theta_{1}$ is the rotational angle of motor, and $\theta_{2}$ is the rotational angle of work roll.

Due to wear of mechanical system, there may be a clearance [22] between gears and universal joint shaft, and its elastic recovery torque is a nonlinear function of rotational angle, as shown in Figure 2. The stiffness coefficient can be expressed in Figure 2 as

$$
K_{12}= \begin{cases}K_{12}-\frac{K_{12} \Delta}{\theta_{1}-\theta_{2}}, & \Delta \leq \theta_{1}-\theta_{2} \leq \infty \\ 0, & -\Delta \leq \theta_{1}-\theta_{2} \leq \Delta \\ K_{12}+\frac{K_{12} \Delta}{\theta_{1}-\theta_{2}}, & -\infty \leq \theta_{1}-\theta_{2} \leq \Delta .\end{cases}
$$

Friction is necessary in rolling process, in a sense that the rolls pull the strip into roll bite by means of friction; meanwhile the lubrication state in roll gap and main drive system has a direct impact on system stability. A former model [23] utilized a constant friction factor approach between the work roll and strip. The constant friction factor model may not be adequate under excellent lubrication conditions, which are exactly happening in the case of high-speed rolling mill configuration. So a dynamic friction model is proposed considering dynamic rolling process and relative speed difference. Then the coefficient can be expressed as follows:

$$
\mu=-c v+d v^{3}
$$

where $c, d$ are variable parameters and $v=R^{\prime} \dot{\theta}_{2}$.

Besides, when the cold rolling mill begins to vibrate, the rolling force in the roll gap is extremely high, leading to the work roll flattening effect, which cannot be neglected because that may significantly reduce the estimate of the actual contact length between the work roll and the strip, then leads to an underestimation of the rolling force. Therefore, a model of the work roll flattening effect which is more proper for practical working conditions has been shown as follows [24]:

$$
R^{\prime}=R\left[1+\frac{16\left(1-v_{1}^{2}\right) f_{y}}{\left(\Delta h+\Delta h_{e}\right) \pi E_{1}}\right],
$$

where $R$ is original radius without working roll flattening effect, $f_{y}$ is the roll force per width, $\Delta h$ is the screw down amount of work roll, $\Delta h_{e}$ is the elastic feedback of the strip, $v_{1}$ is Poisson's ratio, and $E_{1}$ is Young's modulus of the roll material.

Based on the analyses above, the differential equation of two degrees-of-freedom model can be derived as

$$
\begin{gathered}
J_{1} \ddot{\theta}_{1}+C_{1} \dot{\theta}_{1}+K_{12}\left(\theta_{1}-\theta_{2}\right)=M_{1}, \\
J_{2} \ddot{\theta}_{2}+K_{12}\left(\theta_{2}-\theta_{1}\right)+C_{2}{ }^{\prime} \dot{\theta}_{2}=-M_{2} .
\end{gathered}
$$

Then it can be transformed into

$$
\begin{gathered}
J_{1} \ddot{\theta}_{1}+C_{1} \dot{\theta}_{1}+K_{12}\left(\theta_{1}-\theta_{2}\right)=M_{1}, \\
J_{2} \ddot{\theta}_{2}+K_{12}\left(\theta_{2}-\theta_{1}\right)+C_{2} \dot{\theta}_{2}=-M_{2}-f R^{\prime},
\end{gathered}
$$

where $f=\mu P, P$ is rolling force, and $C_{2}$ is the damping coefficient of vertical rolls system. 


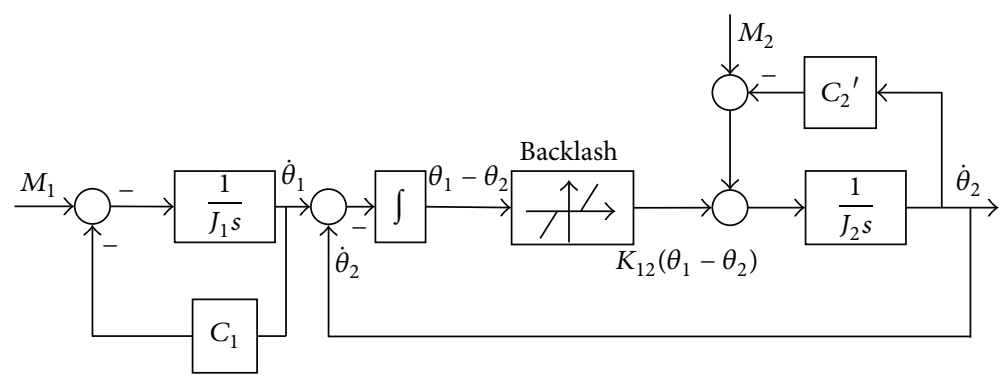

FIGURE 1: Structure of speed control model in main drive system with consideration of nonlinear influence.

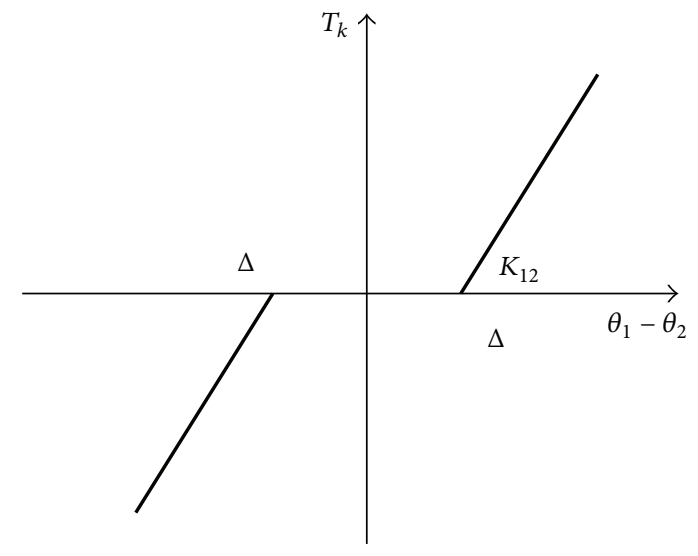

FIGURE 2: The relationship between torsional torque and rotational angle within clearance.

After substitution of (2) into (5), the new form of differential equation can be acquired:

$$
\begin{gathered}
J_{1} \ddot{\theta}_{1}+C_{1} \dot{\theta}_{1}+K_{12}\left(\theta_{1}-\theta_{2}\right)=M_{1}, \\
J_{2} \ddot{\theta}_{2}+K_{12}\left(\theta_{2}-\theta_{1}\right)+\left(C_{2}-c R^{\prime 2} P\right) \dot{\theta}_{2}=-M_{2}-d R^{\prime 4} P \dot{\theta}_{2}^{3} .
\end{gathered}
$$

Define $z_{1}=\Delta \theta=\theta_{1}-\theta_{2}, z_{2}=\dot{\theta}_{1}, z_{3}=\dot{\theta}_{2}$, then $\dot{z}_{1}=\Delta \dot{\theta}=$ $\dot{\theta}_{1}-\dot{\theta}_{2}$.

Equation (6) can be transformed into the three following equations:

$$
\begin{gathered}
\dot{z}_{1}=z_{2}-z_{3}, \\
\dot{z}_{2}=-\frac{K_{12}}{J_{1}} z_{1}-\frac{C_{1}}{J_{1}} z_{2}+\frac{1}{J_{1}} M_{1}, \\
\dot{z}_{3}=\frac{K_{12}}{J_{1}} z_{1}-\frac{C_{2}-c R^{\prime 2} P}{J_{2}} z_{3}-\frac{M_{2}+d R^{\prime 4} P z_{3}{ }^{3}}{J_{2}} .
\end{gathered}
$$

And the torsional vibration torque can be obtained as

$$
M_{12}=K_{12}\left(\theta_{1}-\theta_{2}\right)=K_{12} x_{1} .
$$

2.2. Model Transformation. According to the demand of our control approach, the mathematical model of main drive system has to be transformed into a lower triangular structure.
Define $x_{1}=z_{3}, x_{2}=z_{1}, x_{3}=z_{2}$, and then nonlinear torsional vibration model of main drive system can be expressed as

$$
\begin{aligned}
{\left[\begin{array}{c}
\dot{x}_{1} \\
\dot{x}_{2} \\
\dot{x}_{3}
\end{array}\right]=} & {\left[\begin{array}{ccc}
-\frac{C_{2}-c R^{\prime 2} P}{J_{2}} & \frac{K_{12}}{J_{1}} & 0 \\
-1 & 0 & 1 \\
0 & -\frac{K_{12}}{J_{1}} & -\frac{C_{1}}{J_{1}}
\end{array}\right]\left[\begin{array}{c}
x_{1} \\
x_{2} \\
x_{3}
\end{array}\right] } \\
& +\left[\begin{array}{c}
0 \\
0 \\
\frac{1}{J_{1}}
\end{array}\right] M_{1}+\left[\begin{array}{c}
-\frac{M_{2}+d R^{\prime 4} P x_{1}{ }^{3}}{J_{2}} \\
0 \\
0
\end{array}\right] .
\end{aligned}
$$

2.3. Control Task. Based on (9), the drive torque of motor $M_{1}$ is the controller output. $d R^{\prime 4} P x_{1}{ }^{3}$ is the nonlinear item of variable friction coefficient in dynamic cold rolling process. $M_{2}$ is the load torque within external load disturbance. Due to the variation of thickness and hardness from upstream rolling stands, as well as roll eccentricity, combined with the actual situation in rolling process, the following equation can be obtained:

$$
M_{2}=M_{2}^{o}+M_{2}^{*}=M_{2}^{o}+A \sin (\pi t),
$$

where $M_{2}{ }^{o}$ is the load of rolls side under steady state, $M_{2}{ }^{*}=$ $A \sin (\pi t)$ is the external disturbance, and $A$ is defined as vibration amplitude.

As we can see from (7) and (9)

$$
x_{1}=z_{3}=\dot{\theta}_{2} \text {, }
$$

where $\dot{\theta}_{2}$ is the angular velocity of work roll; we aim at designing a robust controller to have $\dot{\theta}_{2}$ tracking the reference signals. At the same time, it is expected to show good disturbance attenuation performance for nonlinear parameters such as stiffness and friction, as well as load disturbance. 


\section{Control Design Procedure}

Consider a nonlinear plant with lower triangular structure described by the following equations:

$$
\sum x\left\{\begin{array}{c}
\dot{x}_{1}(t)=g_{1}(x, d, t) x_{2}(t)+\phi_{1}(x, d, t) \\
\dot{x}_{2}(t)=g_{1}(x, d, t) x_{3}(t)+\phi_{2}(x, d, t) \\
\vdots \\
\dot{x}_{n}(t)=g_{n}(x, d, t) u(t)+\phi_{n}(x, d, t), \\
y_{p}(t)=x_{1}(t),
\end{array}\right.
$$

where $x_{i}(t)(i=1,2, \ldots, n)$ are the states, $y_{p}(t)$ is the output, $d(t)$ is an external disturbance vector, $g_{i}(x, d, t)(i=$ $1,2, \ldots, n)$ are unknown virtual control coefficients, and $\phi_{i}(x, d, t)(i=1,2, \ldots, n)$ are regarded as nonlinear timevarying uncertainties.

It is expected we will design a linear robust controller within backstepping procedure, which can produce a control input $u(t)$ to drive the output $y_{p}(t)$ of the plant to track a reference output, denoted by $y_{d}(t)$.

The main idea of this control algorithm at each step of backstepping procedure is presented as follows [20]:

(1) firstly, the tracking problem is transformed into a regulation problem;

(2) then the nominal controller is designed to get desired property for the nominal disturbance-free model;

(3) thirdly, the influence of the uncertainties and external disturbance is regarded as an equivalent disturbance;

(4) finally, a robust compensator is designed to restrain the effect of the equivalent disturbance and to achieve robust properties.

Step 1. To start, define the variables below:

$$
\begin{gathered}
\tilde{y}_{1}(t)=y_{p}(t)-y_{d}(t)=x_{1}(t)-y_{d}(t), \\
\tilde{y}_{2}(t)=x_{2}(t)-\widehat{x}_{2}(t),
\end{gathered}
$$

where $\hat{x}_{2}(t)$ is a virtual controller to be designed. Then according to (12) and (14), the subsystem can be established

$$
\dot{\tilde{y}}_{1}(t)=g_{1}(t) x_{2}(t)+\tilde{\phi}_{1}(t)
$$

where $\widetilde{\phi}_{1}(t)=\phi_{1}(t)-\dot{y}_{d}(t)$.

Based on (16), $\widehat{x}_{2}(t)$ can be designed as

$$
\widehat{x}_{2}(t)=-\frac{\alpha_{1}}{\underline{g}_{1}} \tilde{y}_{1}(t)+\frac{f_{1}}{\underline{g}_{1}} w_{1}(t),
$$

where the first item of (17) represents nominal virtual control input to stabilize the nominal subsystem without disturbance and uncertainties and $\alpha_{1}$ is a positive constant. The second item of (17) defines a robust compensator, and $w_{1}(t)$ is the compensating input; $f_{1}$ is also a positive constant to be determined. Substituting (14), (15), and (17) into (16), one can obtain

$$
\dot{\tilde{y}}_{1}(t)=-\alpha_{1} \tilde{y}_{1}(t)+\widehat{\phi}_{1}(t)+f_{1} w_{1}(t)
$$

where $\widehat{\phi}_{1}(t)$ is defined as equivalent disturbance

$$
\widehat{\phi}_{1}(t)=\widetilde{\phi}_{1}(t)+\underline{g}_{1} \tilde{y}_{2}(t)+\left[g_{1}(t)-\underline{g}_{1}\right] x_{2}(t) \text {. }
$$

In order to attenuate and suppress the influence of subsystem robust property by equivalent disturbance, the robust compensating input is constructed as follows

$$
w_{1}(t)=-F_{1}(s) \widehat{\phi}_{1}(t),
$$

where $F_{1}(s)$ is a robust low-pass filter in the following form:

$$
F_{1}(s)=\frac{1}{s+f_{1}}
$$

As shown in (21), if the filter time-constant $f_{1}$ is positive and sufficiently large, we can see that $F_{1}(s)$ is sufficiently small, then one can expect that $f_{1} w_{1}(t)$ would approximate $-\widehat{\phi}_{1}(t)$ and neutralize the effect of equivalent disturbance to gain robust property.

Since $\widehat{\phi}_{1}(t)$ is immeasurable, it can be expressed in the form

$$
\widehat{\phi}_{1}(t)=\left(s+\alpha_{1}\right) \tilde{y}_{1}(t)-f_{1} w_{1}(t) .
$$

To get the robust compensating input $w_{1}(t)$, only $\tilde{y}_{1}(t)$ is needed in the form below:

$$
w_{1}(t)=-\left(1+\frac{\alpha_{1}}{s}\right) \tilde{y}_{1}(t) .
$$

According to those equations above, the subsystem can be established as

$$
\dot{\tilde{y}}_{2}(t)=g_{2}(t) x_{3}(t)+\widetilde{\phi}_{2}(t)
$$

where $\tilde{\phi}_{2}(t)=\phi_{2}(t)-\left(\alpha_{1}^{2} / \underline{g}_{1}\right) \tilde{y}_{1}(t)+\left(\left(f_{1}+\alpha_{1}\right) / \underline{g}_{1}\right)\left[\widehat{\phi}_{1}(t)+\right.$ $\left.f_{1} w_{1}(t)\right]$.

As the second step, the $\widetilde{\phi}_{2}(t)$ item of subsystem (24) will be considered as disturbance and continue the similar design procedure.

Step $i$. Consider the $i$ th subsystem $(i=2, \ldots, n-1)$

$$
\dot{\tilde{y}}_{i}(t)=g_{i}(t) x_{i+1}(t)+\widetilde{\phi}_{i}(t)
$$

where

$$
\begin{aligned}
\tilde{y}_{i}(t)= & x_{i}(t)+\frac{\alpha_{i-1}}{\underline{g}_{i-1}} \tilde{y}_{i-1}(t)-\frac{f_{i-1}}{\underline{g}_{i-1}} w_{i-1}(t), \\
\widetilde{\phi}_{t}(t)= & \phi_{i}(t)-\frac{\alpha_{i-1}^{2}}{\underline{g}_{i-1}} \tilde{y}_{i-1}(t) \\
& +\frac{f_{i-1}+\alpha_{i-1}}{\underline{g}_{i-1}}\left[\widehat{\phi}_{i-1}(t)+f_{i-1} w_{i-1}(t)\right] .
\end{aligned}
$$

Introduce the error variable

$$
y_{i+1}(t)=x_{i+1}(t)-\widehat{x}_{i+1}(t) .
$$


And regard $\hat{x}_{i+1}(t)$ as the virtual control input of the $i$ th subsystem

$$
\widehat{x}_{i+1}(t)=-\frac{\alpha_{i}}{\underline{g}_{i}} \widetilde{y}_{i}(t)+\frac{f_{i}}{\underline{g}_{i}} w_{i}(t),
$$

where $\alpha_{i}$ and $f_{i}$ are both positive constants. Then

$$
\dot{\tilde{y}}_{i}(t)=-\alpha_{i} \widetilde{y}_{i}(t)+\widehat{\phi}_{i}(t)+f_{i} w_{i}(t),
$$

where $\widehat{\phi}_{i}(t)=\widetilde{\phi}_{i}(t)+\underline{g}_{i} \tilde{y}_{i+1}(t)+\left[g_{i}(t)-\underline{g}_{i}\right] x_{i+1}(t)$.

The robust compensating input $w_{i}(t)$ can be expressed as

$$
\begin{gathered}
w_{i}(t)=-F_{i}(s) \widehat{\phi}_{i}(t), \\
F_{i}(s)=\frac{1}{s+f_{i}} .
\end{gathered}
$$

Note that

$$
\widehat{\phi}_{i}(t)=\left(s+\alpha_{i}\right) \tilde{y}_{i}(t)-f_{i} w_{i}(t) .
$$

Therefore, $w_{i}(t)$ can also be given by

$$
w_{i}(t)=-\left(1+\frac{\alpha_{i}}{s}\right) \tilde{y}_{i}(t)
$$

After differentiating $\dot{\tilde{y}}_{i+1}(t)$, one has

$$
\dot{\tilde{y}}_{i+1}(t)=g_{i+1}(t) x_{i+2}(t)+\tilde{\phi}_{i+1}(t)
$$

where $\widetilde{\phi}_{i+1}(t)=\phi_{i+1}(t)-\left(\alpha_{i}^{2} / \underline{g}_{i}\right) \tilde{y}_{i}(t)+\left(\left(f_{i}+\alpha_{i}\right) / \underline{g}_{i}\right)\left[\widehat{\phi}_{i}(t)+\right.$ $\left.f_{i} w_{i}(t)\right]$.

Step n. At the last step, one has

$$
\dot{\tilde{y}}_{n}(t)=g_{n}(t) u(t)+\tilde{\phi}_{n}(t)
$$

where

$$
\begin{aligned}
\tilde{y}_{n}(t)= & x_{n}(t)+\frac{\alpha_{n-1}}{\underline{g}_{n-1}} \tilde{y}_{n-1}(t)-\frac{f_{n-1}}{\underline{g}_{n-1}} w_{n-1}(t), \\
\tilde{\phi}_{n}(t)= & \phi_{n}(t)-\frac{\alpha_{n-1}^{2}}{\underline{g}_{n-1}} \tilde{y}_{n-1}(t) \\
& +\frac{f_{n-1}+\alpha_{n-1}}{\underline{g}_{n-1}}\left[\widehat{\phi}_{n-1}(t)+f_{n-1} w_{n-1}(t)\right] .
\end{aligned}
$$

The real control input $u(t)$ can be constructed including nominal control input and robust compensating input

$$
u(t)=-\frac{\alpha_{n}}{\underline{g}_{n}} \tilde{y}_{n}(t)+\frac{f_{n}}{\underline{g}_{n}} w_{n}(t),
$$

where $w_{n}(t)=-F_{n}(s) \widehat{\phi}_{n}(t), F_{n}(s)=1 /\left(s+f_{n}\right)$.

Note that

$$
\widehat{\phi}_{n}(t)=\widetilde{\phi}_{n}(t)+\left[g_{n}(t)-\underline{g}_{n}\right] u(t)
$$

$w_{n}(t)$ can be expressed as

$$
w_{n}(t)=-\left(1+\frac{\alpha_{n}}{s}\right) \tilde{y}_{n}(t) .
$$

As we can see from (34) and (36), it follows that

$$
\dot{\tilde{y}}_{n}(t)=-\alpha_{n} \widetilde{y}_{n}(t)+\widehat{\phi}_{n}(t)+f_{n} w_{n}(t) .
$$

After summarizing the design results, the following system structure can be established:

$$
\begin{array}{r}
{\left[\begin{array}{c}
\dot{\tilde{y}}_{i}(t) \\
\dot{w}_{i}(t)
\end{array}\right]=\left[\begin{array}{cc}
-\alpha_{i} & f_{i} \\
0 & -f_{i}
\end{array}\right]\left[\begin{array}{l}
\tilde{y}_{i}(t) \\
w_{i}(t)
\end{array}\right]} \\
+\left[\begin{array}{c}
1 \\
-1
\end{array}\right] \widehat{\phi}_{i}(t), \\
i=1,2, \ldots, n .
\end{array}
$$

The whole controller description is

$$
\begin{gathered}
u(t)=-\frac{\alpha_{n}}{\underline{g}_{n}} \tilde{y}_{n}(t)+\frac{f_{n}}{\underline{g}_{n}} w_{n}(t), \\
\tilde{y}_{1}(t)=x_{1}(t)-y_{d}(t), \\
\tilde{y}_{i}(t)=x_{i}(t)+\frac{\alpha_{i-1}}{\underline{g}_{i-1}} \tilde{y}_{i-1}(t)-\frac{f_{i-1}}{\underline{g}_{i-1}} w_{i-1}(t), \\
\quad i=2,3, \ldots, n, \\
w_{i}(t)=-\left(1+\frac{\alpha_{i}}{s}\right) \tilde{y}_{i}(t), \quad i=1,2, \ldots, n,
\end{gathered}
$$

where $\alpha_{i}$ is chosen so that $\tilde{y}_{i}(t)$ has desired convergent speed and $f_{i}$ is needed to be determined to achieve robust stability and robust output tracking properties [20].

\section{Simulation Result and Discussion}

From the design procedure of the control algorithm in the last section, one can notice that the problem of "explosion of complexity" is fully avoided. Meanwhile, less information about reference output as well as the bounds of uncertainties is applied to construct the robust controller. While the price of this solution is that when there is no dynamic uncertainty or external disturbance, the tracking error cannot be guaranteed to converge to zero, it can only be made as small as desired by appropriately choosing controller parameters $\alpha_{i}$ and $f_{i}$. However, due to the actual situation in industrial fields, uncertainty and external disturbance are ubiquitous in dynamic rolling process, especially when the vibration phenomenon begins to emerge. Besides, from (9)(11), one can notice the good applicability of our approach on the mathematical model in main drive system with the consideration of model parametric nonlinearity and external load disturbance.

In order to prove the advantage of control method, a simulation experiment with actual industrial data is built, because the torsional vibration in tandem cold rolling mill usually happens in the latter roll-stand, due to its higher rolling speed and the influence by back tension variations. Therefore, the experimental parameters come from the main 
TABLE 1: Rolling parameters.

\begin{tabular}{lc}
\hline Parameters & Value and unit \\
\hline$J_{1}$ & $1552 \mathrm{~kg} \cdot \mathrm{m}^{2}$ \\
$J_{2}$ & $1542 \mathrm{~kg} \cdot \mathrm{m}^{2}$ \\
$K_{12}$ & $5.93 \times 10^{6} \mathrm{~N} \cdot \mathrm{M} / \mathrm{rad}$ \\
$\Delta$ & $0.1 \mathrm{rad}$ \\
$R$ & $0.4 \mathrm{~m}$ \\
$P$ & $932 \mathrm{KN}$ \\
$c$ & 0.06 \\
$d$ & 0.0024 \\
\hline
\end{tabular}

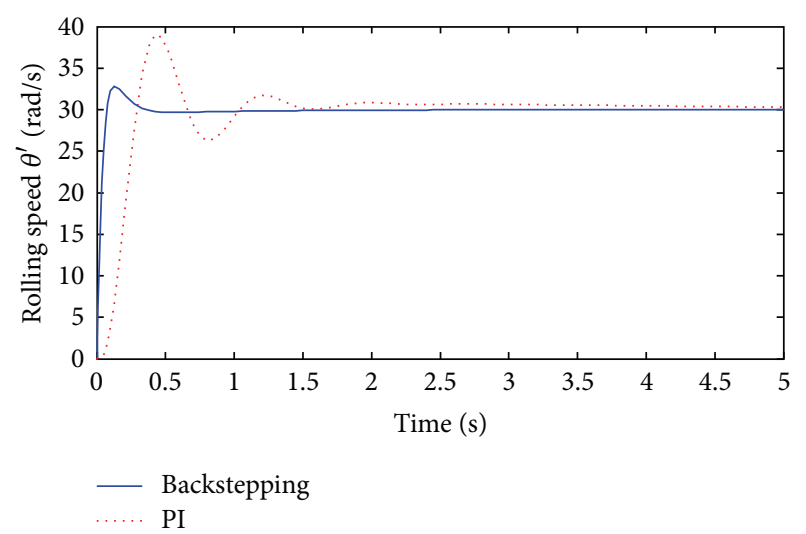

FIGURE 3: Step response of rolling speed within parameter uncertainties.

drive system data in 4 th rolling stand of Baosteel. The major parameters are listed in Table 1.

At first, a comparison between robust backstepping controller and PI is made, that the PI algorithm, which is still widely used in the actual rolling field control system, is derived with application of integral square time error

$$
K_{\mathrm{PI}}=243\left(1+\frac{1}{0.371 s}\right) \text {. }
$$

Based on the results on robust property and selection of control performance index in [20], the two key parameters can be obtained separately: $\alpha_{i}=3(i=1,2,3), f_{1}=10, f_{2}=$ 100 , and $f_{3}=1000$. Let us assume that the operation condition of dynamic rolling mill neglects the influence of load disturbance temporarily, while the parameter uncertainty by variable nonlinear stiffness and friction is considered. Given the system, a unit step response with rolling speed $r=$ $30 \mathrm{rad} / \mathrm{s}$, as shown in Figure 3, although the PI controller is capable of maintaining stable rolling operation in ideal working conditions, which means the system response is not affected by variation of strip thickness or by back or front tension, it is no longer qualified in this situation as its overshoot and regulating time is unacceptable in real industrial rolling process. On the other hand, the control performance of robust backstepping algorithm is still good because of its better suppression capability on parameter uncertainties.

As demonstrated in many papers [1-8] and engineering projects, the roll eccentricity and variation of strip material

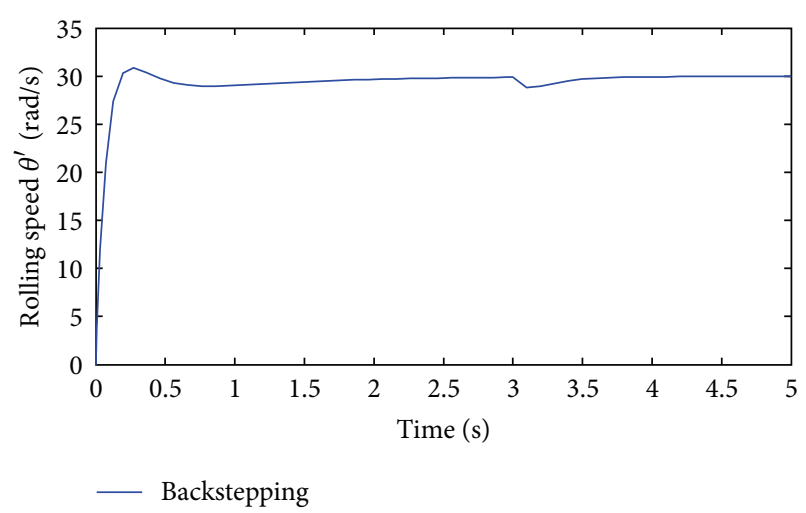

FIGURE 4: Step response of rolling speed under load disturbance.

quality (thickness, hardness, etc.) will lead to motor speed fluctuation, then generate current harmonics and therefore causing the unstable or vibration rolling process within electromechanical coupling in main drive system. Thus, those load disturbances can be derived as sinusoidal disturbance $[25,26]$, and based on the above parameters and process data, the value can be expressed as

$$
M_{2}=M_{2}{ }^{o}+A \sin (\pi t)=[14500+2910 \sin (\pi t)] \mathrm{N} \cdot \mathrm{m} .
$$

Figure 4 shows the system step response when the load disturbance was added at $3 \mathrm{~s}$. During a short-term fluctuation, the system under robust backstepping algorithm returns to normal status quickly, mainly because of low-pass filter and robust compensating input on the attenuation to equivalent disturbance.

\section{Conclusion}

A nonlinear model of cold rolling main drive system has been formulated, including variable stiffness by clearance, changeable friction coefficient with consideration of relative speed between work roll and strip, and the load disturbance with roll eccentricity and variation of strip material quality.

In view of parameter uncertainty and external disturbance in dynamic cold rolling process, the mathematical model is transformed into a lower triangular structure. A robust backstepping method has been introduced to design a robust controller, which contains a nominal controller and a robust compensator, to achieve a robust tracking property for real controlled plant. The simulation results show its good performance on reference signal tracking under different operational conditions. Meanwhile, its linear and timeinvariant characteristic causes the controller to be fulfilled easily.

Despite these encouraging results, the industrial application of this control algorithm should be involved. Due to the existing difficulty, such as nonlinearity, strong coupling features in rolling mill system, and requirement in fast response on control algorithm, the improvements of controller on efficiency and practically would be enormous benefits. Moreover, the possibility for expansion of this robust controller 
in industrial practical plants to improve strip quality is recommended as an important issue for future investigation.

\section{Acknowledgments}

The authors gratefully acknowledge the support by National Natural Science Foundation of China (nos. 51205018 and 61074085), Research Projects of State Key Laboratory of Mechanical System and Vibration (no. MSV-2014-09), China Postdoctoral Science Foundation Funded Project (no. 2012M510321), and Fundamental Research Funds for the Central Universities (nos. FRF-TP-12-104A and FRF-SD12-008B). Meanwhile, great thanks also goes to Baosteel Company in Shanghai, China, for data support, and the anonymous reviewers for their valuable comments and suggestions.

\section{References}

[1] J. X. Zou and L. J. Xu, Vibration in Rolling Mills, pp. 88-107, Metallurgical Industry Press, Beijing, China, 1998, (Chinese).

[2] X. Yang and C. N. Tong, "Coupling dynamic model and control of chatter in cold rolling," Journal of Dynamic Systems, Measurement and Control-Transactions of the ASME, vol. 134, no. 4, Article ID 041001, 8 pages, 2012.

[3] M. N. Skripalenko, M. M. Skripalenko, D. A. Ashikhmin et al., "Wavelet analysis of fluctuations in the thickness of cold-rolled strip," Metallurgist, vol. 57, no. 7-8, pp. 606-611, 2013.

[4] P. V. Krot, "Transient torsional vibrations control in the geared drive trains of the hot rolling mills," in Proceedings of the IEEE Conference on Control Application, Part of 2009 IEEE MultiConference on System and Control, pp. 1368-1373, July 2009.

[5] V. Panjković, R. Gloss, J. Steward, S. Dilks, R. Steward, and G. Fraser, "Causes of chatter in a hot strip mill: observations, qualitative analyses and mathematical modelling," Journal of Materials Processing Technology, vol. 212, no. 4, pp. 954-961, 2012.

[6] Y. Kimura, Y. Sodani, N. Nishiura, N. Ikeuchi, and Y. Mihara, "Analysis of chatter in tandem cold rolling mills," ISIJ International, vol. 43, no. 1, pp. 77-84, 2003.

[7] I. Prihod'ko, P. Krot, K. Solov'yov et al., "Vibration monitoring system and the new methods of chatter early diagnostics for tandem mill control," in Proceedings of the International Conference on Vibration in Rolling Mills, pp. 87-106, London, UK, 2006.

[8] Z. J. Huang, L. X. Gao, and Y. F. Liao, Machinery Vibration Monitoring and Fault Diagnosis, pp. 45-80, Chemical industry Press, Beijing, China, 2010, (Chinese).

[9] W. Liang, J. He, S. Yu, W. Long, and X. Cai, "Electromechanical coupling analysis of cold strip steel temper mill," Journal of Central South University of Technology, vol. 31, no. 1, pp. 78-80, 2000.

[10] S. Yin, S. X. Ding, A. Haghani et al., "A comparison study of basic data-driven fault diagnosis and process monitoring methods on the benchmark Tennessee Eastman process," Journal of Process Control, vol. 22, no. 9, pp. 1567-1581, 2012.

[11] H. Dong, Z. Wang, J. Lam, and H. Gao, "Fuzzy-model-based robust fault detection with stochastic mixed time delays and successive packet dropouts," IEEE Transactions on Systems, Man, and Cybernetics B, vol. 42, no. 2, pp. 365-376, 2012.

[12] S. X. Ding, "Integrated design of feedback controllers and fault detectors," Annual Reviews in Control, vol. 33, no. 2, pp. 124-135, 2009.
[13] H. Dong, Z. Wang, and H. Gao, "Fault detection for Markovian jump systems with sensor saturations and randomly varying nonlinearities," IEEE Transactions on Circuits and Systems I, vol. 59, no. 10, pp. 2354-2362, 2012.

[14] S. Yin, H. Luo, and S. X. Ding, "Real-time implementation of fault-tolerant control systems with performance optimization," IEEE Transactions on Industrial Electronics, vol. 61, no. 5, pp. 2402-2411, 2014.

[15] R. Zhang and C. Tong, "Torsional vibration control of the main drive system of a rolling mill based on an extended state observer and linear quadratic control," Journal of Vibration and Control, vol. 12, no. 3, pp. 313-327, 2006.

[16] E. J. M. Geddes and I. Postlethwaite, "Improvements in product quality in tandem cold rolling using robust multivariable control," IEEE Transactions on Control Systems Technology, vol. 6, no. 2, pp. 257-269, 1998.

[17] R. Freeman and P. Kokotovic, "Backstepping design of robust controller for a class of nonlinear systems," Proceedings of the IFAC Nonlinear Control System Design Symposium, pp. 307-312, June 1992.

[18] Z. Jiang and D. J. Hill, "A robust adaptive backstepping scheme for nonlinear systems with unmodeled dynamics," IEEE Transactions on Automatic Control, vol. 44, no. 9, pp. 1705-1711, 1999.

[19] N. Yagiz and Y. Hacioglu, "Backstepping control of a vehicle with active suspensions," Control Engineering Practice, vol. 16, no. 12, pp. 1457-1467, 2008.

[20] Y. Yu and Y. Zhong, "Robust backstepping output tracking control for SISO uncertain nonlinear systems with unknown virtual control coefficients," International Journal of Control, vol. 83, no. 6, pp. 1182-1192, 2010.

[21] M. Krstic and M. Bernent, "Non-overshooting control of strictfeedback nonlinear systems," in Proceedings of the American Control Conference (ACC '07), pp. 4494-4499, July 2007.

[22] H. Li, G. Meng, Z. Meng, and B. Wen, "Effects of boundary conditions on a self-excited vibration system with clearance," International Journal of Nonlinear Sciences and Numerical Simulation, vol. 8, no. 4, pp. 571-580, 2007.

[23] P. Hu, H. Zhao, and K. F. Ehmann, “Third-octave-mode chatter in rolling. Part 1: chatter model," Proceedings of the Institution of Mechanical Engineers B, vol. 22, no. 8, pp. 1267-1277, 2006.

[24] X. Yang, C. Tong, G. Yue, and J. Meng, "Coupling dynamic model of chatter for cold rolling," Journal of Iron and Steel Research International, vol. 17, no. 12, pp. 30-34, 2010.

[25] R. C. Zhang, Vibration characteristics analysis and control research of the rolling mill electromechanical coupling system [Ph.D. dissertation], University of Science and Technology, Beijing, China, 2006.

[26] S. Mtakula, "An approach of the nonlinear control of rolling mills," in Proceedings of the Advanced Process Control Application for Industry, Workshop of the IEEE Industry Application Society, pp. 1-8, Vancouver, Canada, 2005. 


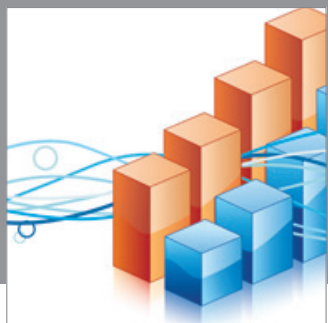

Advances in

Operations Research

mansans

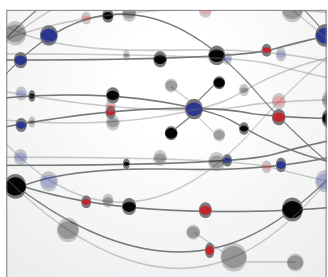

The Scientific World Journal
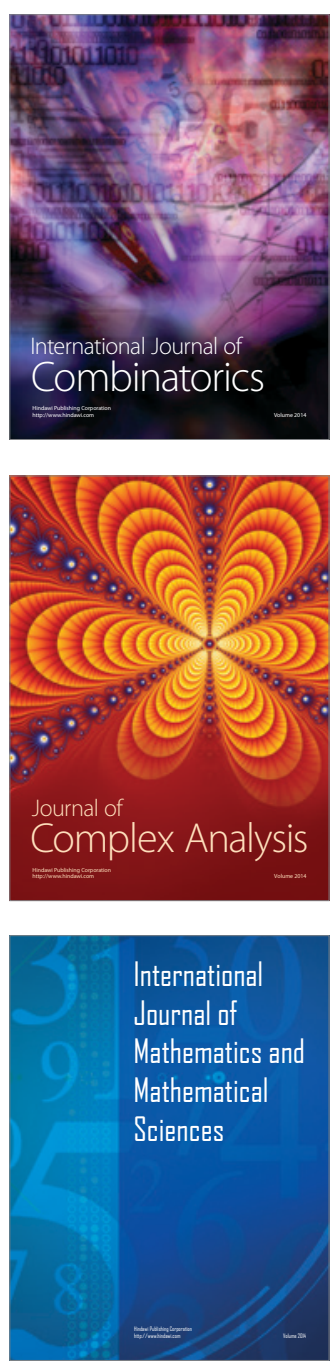
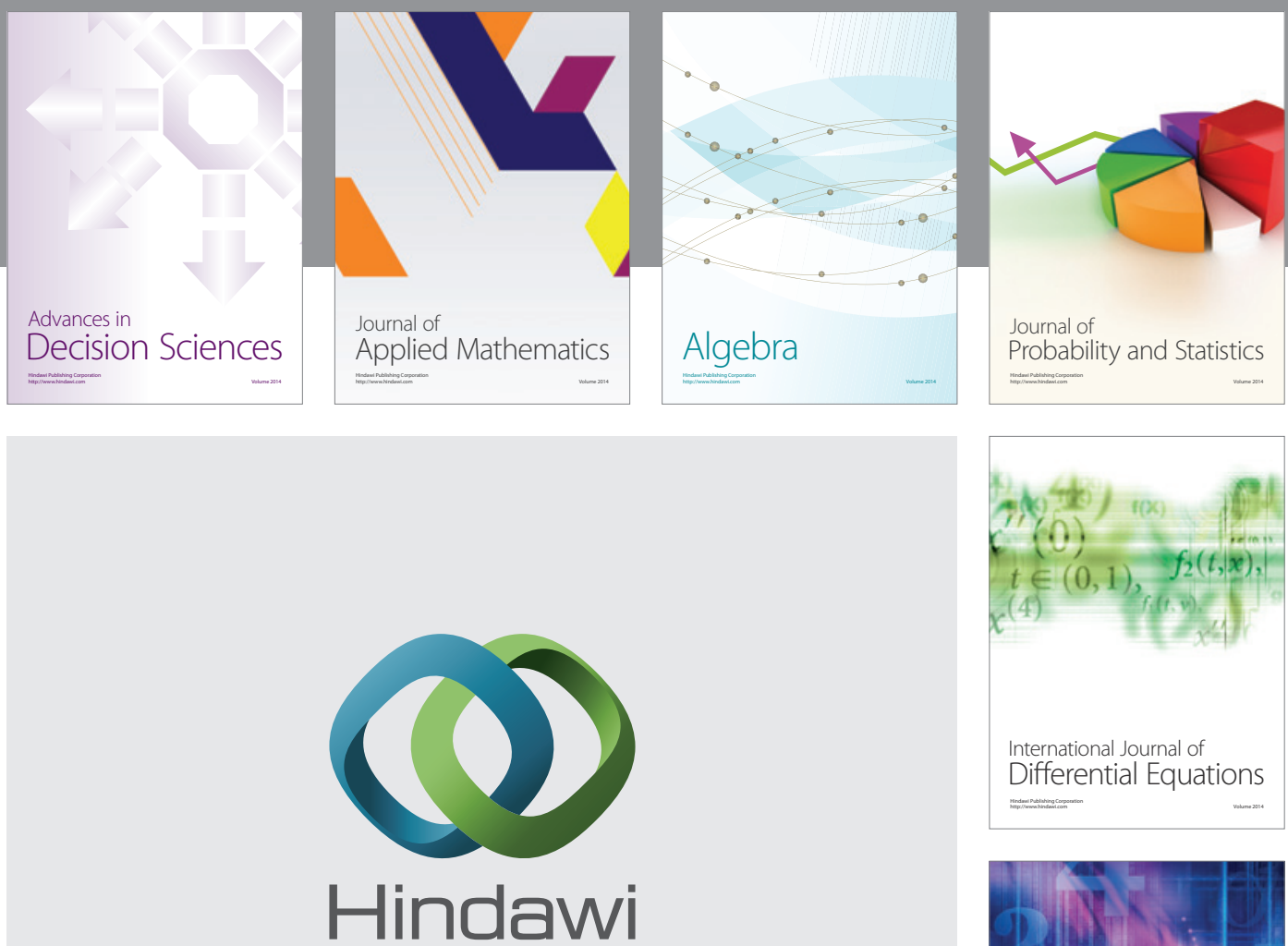

Submit your manuscripts at http://www.hindawi.com
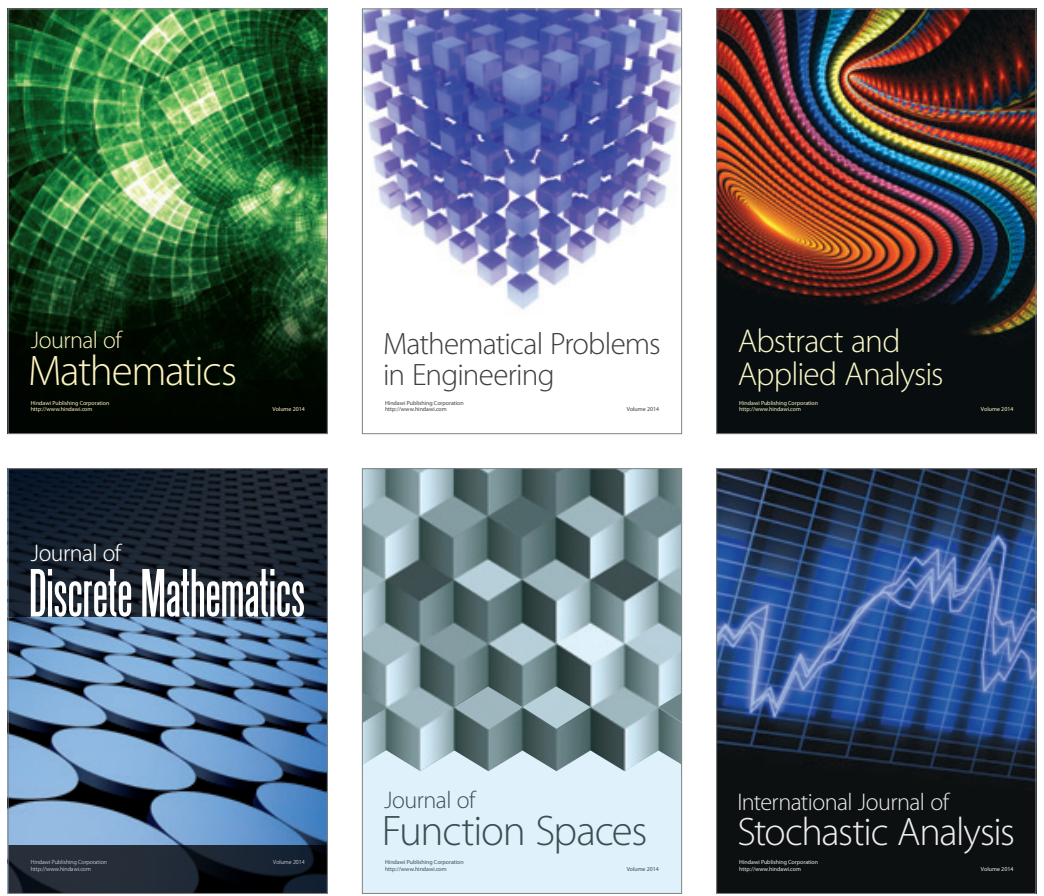

Journal of

Function Spaces

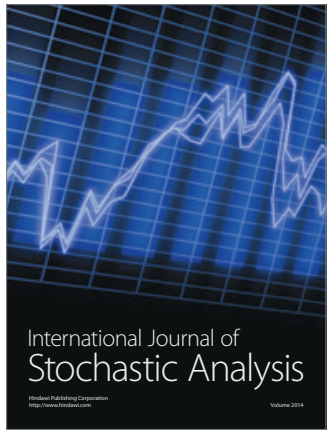

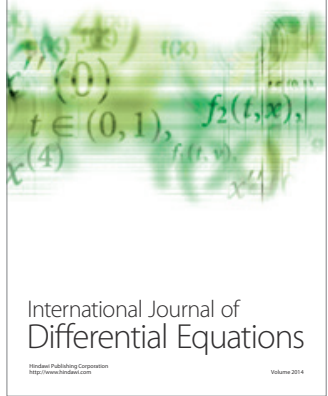
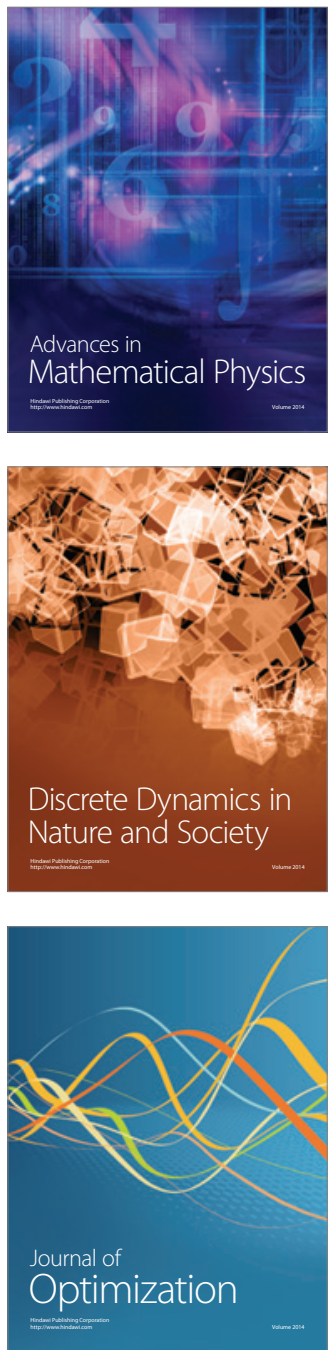